\title{
Espaço urbano: memória social e patrimônio cultural
}

\section{Urban space: social memory and cultural heritage}

\author{
Leonel Brizoll a Monastirsky \\ Universidade Estadual de Ponta Grossa
}

\begin{abstract}
Resumo: Uma forma de análise da organização do espaço urbano se estabelece através da relação entre o espaço, o patrimônio cultural e a memória social. O patrimônio cultural urbano aqui é considerado tanto pelo que ele representa à sociedade, como do ponto de vista da sua ocupação e da sua permanência significativa no espaço e, bem como das ações das políticas públicas relacionadas a esse patrimônio. Assim, esse ensaio propõe algumas reflexões teóricas, adequadas à Geografia Cultural, sobre a organização social do espaço urbano, considerando-se as associações entre o patrimônio cultural e a memória social.
\end{abstract}

Palavras-chave: Espaço urbano. Patrimônio cultural. Memória.

\begin{abstract}
One way to analyze the organization of urban space is to investigate the relationship between space, cultural heritage and social memory. Urban cultural heritage here is considered both for what it represents for the society and what it means from a perspective of occupation, permanence and significant presence in urban space; it is also considered in respect to the actions of public policies in relation to this heritage. Thus, the article proposes some theoretical reflections on the social organization of urban space in the molds of Cultural Geography, focusing on the links between cultural heritage and social memory.
\end{abstract}

Keywords: Urban space. Cultural heritage. Memory.

\section{APRESENTAÇÃO}

A concepção de patrimônio cultural, até a primeira metade do século XX, resumia-se às obras de arte - pintura, escultura e arquitetura - e essas, geralmente, configuravam-se nas obras monumentais, obras de artes consagradas, propriedades de luxo associadas às classes dominantes (BARRETO, 2000). Com a revisão do conceito de cultura, o patrimônio cultural inclui não apenas as manifestações artísticas, mas também os hábitos, os usos e os costumes, as crenças, as formas de vida cotidiana da sociedade e a sua memória. $\mathrm{O}$ patrimônio cultural, que tanto pode conter a cultura erudita quanto a cultura popular, também pode ser identificado nos bens cultural-históricos e nas manifestações sociais atuais.

Com esta ampliação conceitual, o patrimônio cultural apresenta-se como um componente interessante para a análise da organização do espaço. A constituição do espaço, que é historicamente produzida, também pode ser entendida a partir da funcionalidade e dos significados que o patrimônio cultural revela ao longo da sua história - da origem ao tempo presente. $\mathrm{O}$ patrimônio cultural-histórico é, portanto, 
constituído através dos estratos do tempo, mas também, pelos "olhares" do presente que, associados, compõem diversos desdobramentos conceituais sobre ele e sobre o espaço em que está inserido.

Esses componentes, denominados de traços, compõem a coesão de tempos diferentes no presente (LEPETIT, 2001) e formam o conjunto de fragmentos dissonantes de que as cidades são feitas. $\mathrm{O}$ traço resulta de um distanciamento entre ritmos de evoluções diferentes.

A apropriação do espaço implica a constante revivificação dos traços. Essa forma herdada atribui ao espaço uma funcionalidade que está em constante movimento, pois o uso da herança é realizado pela sociedade vigente. Todas as formas de apropriação do espaço - delimitação, ocupação, expulsão, construção, destruição, transformação etc - são realizadas basicamente em função dos mecanismos de mercado e das decisões políticas - as práticas de poder da sociedade naquele determinado momento.

A própria relação do espaço com a sociedade, passando pela memória, torna-se um traço a ser considerado. Há, portanto, uma história/memória de um espaço, por sua genealogia e o resultado da história das relações desse espaço com a sociedade. E esses espaços associam-se à sociedade e se destacam no meio urbano especialmente por apresentarem um suporte patrimonial - seja ele material e/ou intangível.

As discussões a respeito do patrimônio cultural e da memória têm sido cada vez mais pertinentes devido à ampliação das relações estabelecidas com a cultura na chamada era da indústria cultural e da mundialização cultural. Há um novo fascínio pela história neste final/início de século em função de que a velocidade das mudanças que as sociedades experimentam nos últimos tempos, promovidas pela globalização, causa impactos sobre a constituição da identidade, tanto individual quanto coletiva (FREIRE; PEREIRA, 2002). Porém, mesmo com a afirmação em Freire e Pereira, de H. ROUSSO ${ }^{1}$ de que nunca a demanda social da história - memória, presença do passado - esteve tão forte, nunca foi parte tão integrante da cultura, nem tão valorizada, experimenta-se também um processo inverso, ao menos em países periféricos, de uma verdadeira eliminação do passado, um desejo e uma expectativa pelo novo. Essa ambivalência, que se dá em cada lugar segundo uma lógica particular de organização, pressupõe um confronto.

Com este paradoxo, o conflito competitivo entre o velho e o novo, entre a ordem herdada e a ordem projetada (SOJA, 1993), sobre a valorização/participação da história na cultura - por desdobramento: da memória social e do patrimônio cultural -, reafirma-se a necessidade de novos enfoques intelectuais para o tema. Um objeto de conhecimento que só pode ser analisado através de processos constitutivos das ciências humanas e, neste caso, com uma visão particular da Geografia.

\section{MEMÓRIA SOCIAL}

O reconhecimento do patrimônio cultural se estabelece pela identificação dos seus significados. A percepção da carga simbólica contida em cada patrimônio auxilia a desvendar o significado histórico-social deste patrimônio. $\mathrm{O}$ valor simbólico que é atribuído aos objetos decorre da importância que lhes atribui a memória coletiva (ARANTES, 1984). E é esta memória que impele a ver o passado e a inventar o patrimônio dentro dos limites possíveis estabelecidos pelo conhecimento.

\footnotetext{
1 ROUSSO, H. Usos do passado na França de Hoje. In: SIMSON, V. MORAES, O. Os desafios contemporâneos da história oral. Campinas: CMU/UNICAMP, 1997. ROUSSO, H. Usos do passado na França de Hoje. In: SIMSON, V. MORAES, O. Os desafios contemporâneos da história oral. Campinas: CMU/ UNICAMP, 1997.
} 
Com relação ao patrimônio histórico cultural urbano, consideram-se as informações históricas dadas, mas também, e principalmente, a memória (associada ou diferenciada da história). Assim, a memória utilizada como um instrumento de construção cultural apresenta-se como método de análise. Não se trata de fazer uma história nova - impossível segundo François Furet (1988) -, mas permitir que a memória, ainda que possivelmente exagerada, desvirtuada ou mentirosa para a História, contribua para ampliar a apreensão sobre o patrimônio cultural.

\section{Está dada a ordem de lembrar}

Até o século XIX - no Brasil, por exemplo -, pode-se afirmar que um cidadão ao envelhecer era tido como referência junto aos seus descendentes e à sociedade na qual estava inserido. Isso acontecia porque as mudanças tecnológicas, sociais e culturais não eram rápidas o suficiente para excluí-lo de um modelo de vida vigente, e a sua participação efetivava-se por ele ainda estar consciente e participativo das coisas do seu espaço e do tempo presente, que eram praticamente as mesmas coisas do tempo e do espaço de toda a sociedade.

A partir do século XX, com o aumento da velocidade das inovações tecnológicas, iniciou-se um descompasso entre o tempo da sociedade capitalista industrial e o tempo do indivíduo: "tempo da família e tempo industrial" HAREVEN (1982), "tempo rápido e tempo lento" SANTOS (2002). Acompanhando esse desalinho temporal, há também, e associado a isto, um estranhamento espacial, experimentado em algum sentido, diante do processo da globalização.

Esse panorama proporciona a desvinculação das gerações presentes com as gerações passadas, ou "uma destruição dos mecanismos sociais que nos vinculam às gerações passadas" (HOBSBAWM, 1995, p. 13). A sensação da perda de referências e o desligamento com o passado, diante da "aceleração do tempo", levam à necessidade de aproximação e recuperação deste passado. Este sentimento de desaparecimento rápido e definitivo está associado à preocupação com o exato significado do presente e com a incerteza do futuro (NORA, 1993).

Manter a continuidade do presente com o passado - e com um devir futuro - é uma tendência cultural ampliada no final do século $X X$, porém, mais presente nos países centrais. Essa sensação de história acelerada já vem desde o início da industrialização, quando se originou um comportamento nostálgico, marcado pela moda retro, pelo gosto da história, arqueologia, do folclore, da fotografia e também o prestígio ao patrimônio (LE GOFF² citado por FELIX, 1998, p. 54). A sensação de risco de perda das referências histórico-afetivas aumenta gradativamente quando se aumenta a sensação do "tempo rápido".

A preservação da memória e do patrimônio é uma tendência que se constitui nos países periféricos com algum atraso e em situação conflituosa. No âmbito geral, em nosso tempo e em nosso espaço - o brasileiro -, a memória dicotomiza-se entre a sua participação na reconstrução histórica para manter vivo o vivido, a tradição e a genealogia identitária diante à aceleração do tempo e o risco da perda das referências, e na desconsideração e indiferença dada à memória, com a inconsciente valorização do novo em detrimento ao velho, provocada pela irresistível lógica do "progresso" e do "desenvolvimento" social e econômico.

De qualquer maneira, está dada a ordem de lembrar - uma característica pós-mo-

2 LE GOFF, J. Memória. In: Enciclopédia Einaudi. Lisboa, 1984 
derna da virada do século - que enaltece a necessidade de (re)conhecer estágios passados no processo contínuo da história e que gradualmente está se incorporando às necessidades sociais da população brasileira e das políticas públicas.

\section{Memória e história}

Memória e história são antônimas (NORA, 1993, p.23). A história como relato, disciplina ou gênero, com regras, instituições e procedimentos próprios, não pode suplantar a memória coletiva (FÉLIX, 1998). Tradição, memória e história são as três posições diferentes com que o presente vê o passado: a tradição santifica o passado e justifica o status-quo, a memória petrifica e estratifica este passado, enquanto a história é analítica e crítica a ele (RODRIGUES ${ }^{3}$ citado por FELIX, 1998, p. 44).

História e memória possuem, portanto, significados diferentes e se apresentam eficazes metodologicamente ao serem usadas com distinção e/ou compiladas, dependendo do sentido da pesquisa ${ }^{4}$. Enquanto a história permite sistematizar o passado, oferecendo dados pontuais, causas e conseqüências, a memória permite uma compreensão ora complementar ora diferenciada à história, por apresentar laços afetivo-emotivos e de pertencimento social.

A associação das idéias entre "Memória e história: a problemática dos lugares" (NORA, 1993) e "História e memória: a problemática da pesquisa" (FÉLIX, 1998) permite estabelecer as diferenças entre os conceitos, enquanto referencial metodológico e de análise.

3 RODRIGUES J. H. A tradição, memória e história. Brasil tempo e cultura 3, João Pessoa, 1980.

4 Distinção básica entre memória e história, iniciada por Halbawachs, também realizada pelos historiadores Nora (1984), Le Goff (1988), Davis (1989), Rousso (1996; 1998) e Pomian (1999).
A memória, por seus laços afetivos e de pertencimento, é aberta e em permanente evolução e liga-se à repetição e à tradição, sacralizando o vivido do grupo social. A história, ao contrário, dessacraliza a memória, constituindo-se tão somente em representação do passado. A memória se enraíza no concreto, no espaço, no gesto, na imagem, no objeto. A história liga-se às continuidades temporais, às evoluções e às relações das coisas. A memória é a vida, sempre carregada por grupos vivos e, neste sentido, em permanente evolução, aberta à dialética da lembrança e do esquecimento, inconsciente de suas deformações sucessivas, vulneráveis a todos os usos e manipulações, susceptível de longas latências e de repentinas revitalizações. A história é a reconstrução sempre problemática e incompleta do que não existe mais. A memória é um fenômeno sempre atual, um elo vivido no eterno presente, enquanto que a história uma representação do passado. Porque é afetiva e mágica, a memória não se acomoda a detalhes que a confortam e se alimentam de lembranças vagas, telescópicas, globais ou flutuantes, particulares ou simbólicas, sensível a todas as transferências, cenas, censuras ou projeções. A história, porque operação intelectual e laicizante, demanda análise e discurso crítico. A memória instala a lembrança no sagrado; a história a liberta e a torna sempre prosaica. A memória emerge de um grupo que ela une, o que quer dizer, como Halbwachs o fez, que há tantas memórias quantos grupos existem; que ela é, por natureza, múltipla e desacelerada, coletiva, plural e individualizada. A história, ao contrário, pertence a todos e a ninguém, o que lhe dá uma vocação ao universal. A memória é um absoluto e a história só conhece o relativo. A memória perdura-se em lugares, e a história, em acontecimentos. 


\section{Lembrar e esquecer: o jogo da memória}

A análise das várias significações que o patrimônio cultural, e neste caso, especialmente o patrimônio cultural histórico, possa apresentar implica considerar também as diferentes interpretações que o patrimônio tem para os agentes interventores - e as ações que possam se desdobrar dessas interpretações.

Entre as forças de intervenção, as mais efetivas estão relacionadas ao poder público e com o poder do capital - associados na maioria dos casos. Em ambas, a determinação do que deve ser considerado patrimônio, e, posteriormente, como se realiza o processo de preservação e uso passa por uma seqüência de escolhas: a indicação do patrimônio a ser preservado, o conceito de preservação, a técnica de restauração e a utilização. Contido neste processo e relativo à memória, determina-se também essa mesma seqüência para o que será lembrado e o que não será.

Josaida Gondar (2000) contribui nesta questão, ao apresentar uma interessante reflexão sobre o conflito simbólico entre a lembrança e o esquecimento, através de Nietzsche e Freud, afirmando que o esquecimento é necessário, não apenas para a evocação da lembrança, mas para a própria constituição da memória, ou seja, a memória é construída através da escolha do que se quer esquecer.

$\mathrm{O}$ ato de esquecer para construir uma memória pode ser subjetivo, como, por exemplo, o sentimento de orgulho que enaltece apenas a imagem favorável da representação de si mesmo (no plano do Estado, da sociedade ou do indivíduo), e objetivo, quando determinada faceta da memória é mantida, enfatizada ou distorcida para atender a objetivos preestabelecidos.

A idéia de que a recuperação da memória, articulada para reproduzir uma interface da cultura local e atender inicialmente aos interesses econômicos e/ou ideológicos, para posteriormente efetivar-se como um instrumento de reconhecimento identitário e educacional para o cidadão é muito perigosa. Se a preservação do patrimônio for realizada em função desses interesses, poder-se-á ter uma lembrança favorável, única, compatível e útil apenas para o processo de supervalorização da história e da função comercial prevista para o patrimônio.

Desta forma, não se pode falar de memória, articulando-a à identidade, sem inseri-la num afrontamento de forças e sem levar em conta que a memória é, antes de qualquer coisa, um instrumento de poder (GONDAR, 2000). Seria necessário, então, criar instituições capazes de preservar o patrimônio cultural, protegendo as lembranças e documentos do fluxo natural da entropia e dos interesses do capital.

Portanto, se a memória social reflete também a valorização que a sociedade dá ao passado, ela será tão mais significativa quanto mais representar o que foi vivido pelos diversos segmentos sociais, e, quanto mais mobilizar o mundo afetivo dos indivíduos, vasculhando as suas lembranças particulares, o passado é reconstruído plenamente. É necessário anteriormente entender o patrimônio como uma oportunidade de identificação de cidadania, reconhecimento, continuidade histórica, possibilidade de vários olhares e várias interpretações.

A sustentação do patrimônio culturalhistórico, em sentido amplo, faz parte de um processo mais complexo do que a simples conservação e recuperação deste patrimônio. É uma necessidade de sobrevivência cultural, em face da globalização (BARRETO, 2000, p32) e da tendência dos moradores de muitas cidades brasileiras médias e pequenas em considerar, num primeiro momento, que os bens patri- 
moniais representam um entrave para a "modernização" e para o "progresso" e, numa outra fase, quando este patrimônio torna-se fonte de renda e que a sua função não deva ser contestada.

Neste sentido, o direito à memória deve ser preservado, e o arranjo da cidade, através das políticas públicas, deve contemplar este direito. Entretanto, este direito não é dado, mas necessita ser construído, pois, se a memória articulada à identidade é um instrumento de poder, ela será um elemento importante nas constantes disputas que determinam os destinos das cidades (SANTANA, 2000). O patrimônio cultural, portanto, será em qualquer sociedade o produto de uma escolha.

\section{Memória e cidadania: memória coletiva e memória individual}

A associação da própria memória à memória da sociedade na qual o indivíduo está inserido possibilita a ele o reconhecimento da sua identidade, a sensação de aceitação e de participação social, por conseguinte, permeia o exercício da cidadania.

O pertencimento cultural advém da referência que a memória individual encontra na história e na memória coletiva. A memória coletiva é formada pela convergência e aglutinação das várias memórias singulares - sem necessariamente de haver equanimidade temporal - ao mesmo tempo em que transcende ao singularismo. $\mathrm{O}$ conceito de memória coletiva, de Maurice Halbwachs (1990), refere-se a uma memória social, exterior ao indivíduo, estendida no tempo, que guarda eventos acontecidos há muito. Essa memória é o invólucro das memórias individuais e conserva os fatos acontecidos na sociedade à qual o indivíduo pertence.
A memória coletiva transcende o indivíduo ao apresentar uma ordem instituída, normativa à cultura local e às singularidades que a compõem. Este decurso auxilia na formação da consciência coletiva, que pode se moldar através de uma ordem institucionalizada - geralmente pelo poder público local - e/ou como um instrumento de defesa da autonomia cultural.

Neste sentido, o comentário de Émile Durkheim ${ }^{5}$, citado por Denys Cuche (2002), é apropriado ao afirmar que existe em todas as sociedades uma consciência coletiva ${ }^{6}$, feita de representações coletivas, dos ideais, dos valores e dos sentimentos comuns a todos os indivíduos. Ela precede o indivíduo, impõe-se a ele, é exterior a ele. Neste sentido, há descontinuidade entre consciência coletiva e a consciência individual, e a primeira é superior à segunda, por ser mais complexa e indeterminada, além de ser a responsável pela unidade de coesão de uma sociedade.

Com a consciência coletiva, a sociedade mantém viva a memória coletiva, promove a disseminação da sua cultura e conserva o seu patrimônio, e é com a memória individual que o cidadão reconhece a si mesmo neste contexto, pois através do reconhecimento individual cada cidadão sentir-se-á alentado em lutar pelo direito à cidade - direito que não é dado e sim conquistado, num campo aberto aos vários interesses da sociedade capitalista.

A memória efetiva-se de forma subjetiva, porém se utiliza de objetos concretos para a sua sustentação. $\mathrm{O}$ indivíduo necessita guardar, arquivar, registrar fatos, momentos, sensações que possibilitem a percepção da identidade em um processo que tem como orientação a continuidade e a permanência da memória coletiva.

\footnotetext{
5 DURKHEIM, E. Les formes élémentaires de la vie religeuse. Paris, 1960

6 O autor também faz referência ao termo "personalidade coletiva".
} 
Um indivíduo sem memória - ou que, embora tenha registros e os traz de forma incompreensível até para ele mesmo - é um ser sem significado. A luta pelo direito à cidade, que contém a luta pelo direito à memória, tem então como ponto de partida o reconhecimento da memória individual na memória coletiva.

Os destinos da cidade estão em constante disputa e cabe aos cidadãos orientarem este movimento a partir de sua força organizativa e da definição de suas prioridades, não em termos de sua desigualdade, mas de sua igualdade. Neste sentido, completa Márcia Santana (2000, p. 52), a memória pode e deve ser um elemento constante nas preocupações e projetos dos atores sociais.

\section{Memória e o espaço urbano - lugares de memória}

"A memória perdura-se em lugares, como a história em acontecimentos" (NORA, 1993, p.25).

A afirmação de Pierre Nora, que completa o rol de distinções entre história e memória (supracitado), estabelece uma relação estreita entre a memória e o lugar. O autor afirma que os lugares de memória são, antes de tudo, restos ${ }^{7}$. Tanto em Pierre Nora (1993), quanto em Bernard Lepetit (2001), traços ou restos são fragmentos advindos de diversos momentos do passado, os quais o momento presente invariavelmente classifica com a mesma ou nenhuma temporalidade.

Para a determinação de um lugar de memória, Nora (1993) aponta para a necessidade de se manter a intenção de que o lugar seja um lugar de memória. A razão fundamental de ser de um lugar de me-

$7 \mathrm{O}$ conceito de Nora para restos assemelha-se ao de traços de Lepetit (2001, p. 180) fragmentos herdados dissonantes de que as cidades são feitas. mória é poder parar o tempo, bloquear o trabalho do esquecimento, fixar um estado de coisas, imortalizar a morte, materializar o material, prender o máximo de sentido num mínimo de sinais.

O lugar de memória possui uma representatividade própria, identidade única. É fechado em si mesmo, mas aberto às descobertas de suas significações. É dialético, especialmente em relação às memórias individuais - o lugar tem um sentido das coisas que, muitas vezes, só é inteligível para os membros do grupo diretamente relacionados a ele. É desta forma que um lugar de memória, ao apresentar uma memória coletiva, pode confirmar ou reajustar uma memória individual, sem que, necessariamente, seja este um processo irrepreensível e inquestionável, apesar de legítimo. Assim, se os lugares de memória necessitam de intenção para a sua existência, então eles não existem por si mesmos, da mesma forma que não podem ser considerados como resultado de um processo espontâneo.

Auterives Maciel (2000) ${ }^{8}$ contribui para este raciocínio ao apresentar, nos estudos sobre a nomadização dos espaços urbanos, que a organização do espaço urbano acontece concomitantemente com o comportamento dos habitantes neste espaço. A vida cotidiana, normatizada através de um comportamento que, invariavelmente é realizada por uma memória, estabelece a organização do espaço.

A sociedade toma para si o espaço, adaptando-o à sua imagem, a partir das transformações impostas por ela na cotidianidade. Esses lugares especiais de memória poderão transformar-se em lugares eficazes, ou "regiões eficazes", onde "melhor se manifesta a realização, não mais da conservação sistemática dos objetos e dos lugares, mas das representações da gênese das singularidades culturais" (JEUDY,1990,

8 Fundamentado nos conceitos de espaços lisos e estriados de Deleuze e Guattari. 
p.41). E essa genealogia pode estar, como indica CUCHE (2002, P. 180), na hereditariedade, na língua, na cultura, na religião, na psicologia coletiva e no vínculo com o território.

Desta forma, todo lugar apresenta sedimentação histórica e, portanto, várias memórias. A diferença entre os lugares, por este viés, é que a memória de cada lugar pode ser mais ou menos privilegiada, enfatizada, considerada segundo o resultado dos embates entre os atores sociais. O lugar é definido, segundo a memória "escolhida".

Todavia, se todos os lugares são lugares de memória, potencialmente tudo poderia ser preservado. $\mathrm{O}$ excesso, a liberação infinita de todas as memórias ameaça o êxito e a gestão da própria memória (JEUDY,1990). É necessário, portanto, que as escolhas das memórias seja o resultado de um processo (democrático) que evite a banalização da memória, ou a dessacralização do patrimônio, como sugere (FONSECA, 1997). Neste sentido, obter-se-á maior luz sobre a memória, o lugar de memória e o patrimônio.

\section{PATRIMÔNIO CULTURAL: ESCOLHA, PRESERVAÇÃO E USO}

A difusão do patrimônio cultural está atrelada às nuances de interpretação que o patrimônio apresenta (especialmente com relação à memória) e às interferências postas em curso por instituições que regulam o processo de escolha, preservação e uso. Considerar a participação do Estado e das forças do capital na ingerência do patrimônio cultural, tanto no tempo pretérito quanto no tempo presente é imprescindível, pois é a ação conjunta desses dois agentes que melhor determina o caráter do patrimônio cultural das cidades brasileiras. E nesse sentido há uma alteração das políticas públicas nacionais com relação ao patrimônio cultural, pois em cada época (e em cada lugar) têm-se uma idéia sobre o que deve ser preservado.

Em cada época a sociedade e autoridades têm uma idéia sobre o que deve ser preservado. Antes dos anos 30, achava-se que nada tinha para ser preservado. Depois passou-se a defender a preservação do período colonial (cidades mineiras e igrejas barrocas). Atualmente, o patrimônio arquitetônico está conectado não só com o passado e a memória nacionais, mas também com a vida dos moradores da cidade. O conjunto urbanístico, assim como a paisagem está fazendo parte do patrimônio cultural que se inter-relaciona com a noção de espaço turístico. (OLIVEIRA, 2002, p. 11).

Desta forma, mesmo sendo a preservação ${ }^{9}$ do patrimônio cultural uma prática social, em que o processo exige ser aceito e constantemente reiterado pela sociedade, a sua constituição e defesa esbarram em questões ideológicas.

O patrimônio cultural, diretamente relacionado à memória coletiva, é sempre produto de uma escolha e, portanto, tem um caráter arbitrário. Todas as ações políticas e sociais, resultado das lutas políticas e ideológicas, conduzem para uma maior ou menor intervenção no processo de ressignificação do patrimônio cultural.

O patrimônio passou a ser uma construção social de extrema importância política, pois significa a constituição de algo que será a representação do passado histórico e cultural de uma sociedade e, neste sentido, a palavra patrimônio indica escolhas oficiais, que envolvem exclusões - num processo associativo e semelhante à memória. O caráter sedutor que o assunto passa a ter revela-se perigoso, pois pode ocasionar inadequada apropriação política

\footnotetext{
9 Entende-se por "política de preservação" a reunião dos princípios específicos de preservação do patrimônio: conservação, documentação, aquisição, processamento técnico, pesquisa, acesso, disseminação, treinamento, restauração e segurança do patrimônio (BARROS e PACHECO, 1995 citado por CHAGAS, 2003, p. 165).
} 
da questão, o que pode incorrer no desvio de uma reflexão mais adequada e profunda (PINHEIRO, 2002).

Esta herança (memorial/patrimonial) à medida que se articula com fatos, acontecimentos e conjunturas políticas, torna-se vulnerável às ações políticas em todas as escalas. Neste sentido, a análise do patrimônio cultural necessita de um desdobramento escalonar e a determinação da escala determina também a escolha de um sujeito, tanto quanto determina o modo e o campo de confrontação (VAINER, 2001).

Associados à questão ideológica existem ainda problemas estruturais de ordem funcional e burocrática do poder público. A falta de uniformidade de ação entre as escalas de poder, quanto à política de preservação do patrimônio, causam ações conflituosas. Em alguns casos ocorrem intervenções pontuais que dificultam projetos mais amplos; em outros, a imposição de projetos maiores aniquilam com a singularidade do patrimônio local/regional ${ }^{10}$.

Mesmo existindo órgãos e programas nacionais que atendam ao patrimônio, é impossível para eles determinarem sempre o que é significativo para a localidade, e, neste sentido, a participação das prefeituras, câmara de vereadores e sociedade organizada são fundamentais. Além de apresentar esta desconexão, o Estado atua na organização das relações ideológicas (a partir da ideologia dominante), que resulta na delimitação e reprodução das classes sociais. Isto consagra e legitima o processo econômico e as relações de produção como poderes. A constituição de um "Estado-sábio-locutor" implica a efetivação e domínio

10 Discernimento adquirido pelo autor através da experiência como membro do Conselho Municipal do Patrimônio Cultural e Artístico de Ponta Grossa (representante da UEPG), entre 2004 e 2009 de um saber e de um discurso (investidos na ideologia dominante ou constituídos a partir dela), em que as massas populares são excluídas (POULANTZAS, 1985).

Nestes termos, por força da atuação do Estado, determina-se a escolha do que deve ser lembrado/esquecido e a forma de uso do patrimônio, em função de interesses ideológicos e econômicos, ainda que um dos momentos essenciais em todo o seguimento de escolha, preservação e uso do patrimônio cultural seja o da genealogia da memória, cujo processo apresenta-se como um campo de investigação permanente.

\section{CONSIDERAÇÕES FINAIS}

O patrimônio cultural torna-se incorporado à sociedade quando, associada a ele, a memória social é fixada através de elementos que possuem significado para a vida coletiva.

A importância do patrimônio cultural para a sociedade está diretamente relacionada à carga simbólica que este patrimônio representa e com o poder de pertencimento que ele proporciona. A vida social, além de basear-se em organizações hierárquicas institucionalizadas, implica, também, que os indivíduos sintam-se pertencentes a um mesmo conjunto cultural, através da história, da representatividade do patrimônio histórico e cultural que, associado a uma base territorial, constrói a identidade cultural (CLAVAL, 2002). "Com o neoliberalismo, há o desaparecimento progressivo dos universos autônomos de produção cultural. [...] O patrimônio cultural, já posto, é um resgate, confirmação de uma cultura local" (BOURDIEU, 2001, p.144). A banalização e a estandardização da cultura mundializada têm motivado maior preocupação pela conservação dos conjuntos patrimoniais culturais. É uma forma de defesa do lugar, através da ma- 
nutenção da cultura local (patrimônio cultural) diante do processo da globalização (ROCHA, 2009).

No caso do espaço urbano e a sua vinculação específica com o patrimônio cultural, a identificação e interpretação dos elementos descritíveis e quantificáveis que apresentam forma e caráter (acervo material) necessitam buscar nos processos culturais da sociedade apoio para a sua completa apreensão ${ }^{11}$. Considerar a interpretação subjetiva (memória, simbologia, sentimentos etc.) é permitir associar diferentes planos de percepção sobre a apropriação do espaço e do patrimônio.

O espaço, neste contexto, é formado por formas visíveis que lhe conferem certa estabilidade temporal e pela subjetiva estrutura social (cultural). Os movimentos da estrutura social, sua dinâmica, apresentam, constantemente, necessidades novas, novos valores e, com isso, redefinem a organização do espaço.

A designação ativa do espaço, a divisão e a reivindicação do espaço por uma multidão de atores e instituições produziu o que denominou Henry Lefebvre ${ }^{12}$, citado por Mark Gottdiener (1993, p.130), uma "explosão de espaços", resultado da articulação múltipla das relações sociais estratificadas com o espaço. Esses espaços demarcam as distinções entre pessoas e grupos da sociedade que, contraditórios, constituem um conflito sócio-espacial.

Assim, o conceito de marco e de limite passa a ser uma referência à ordem estabelecida. "Todo e qualquer grupo humano exerce algum tipo de atividade de colecionamento de objetos materiais, cujo efeito é demarcar o domínio subjetivo em oposição

11 Característica do "Humanismo" - uma das principais escolas do marxismo ocidental de vocação dialética.

12 LEFEBVRE, H. Space: social product and use value. Nova Yorque, 1979. a um determinado 'outro'. O resultado desta atividade é precisamente a constituição de um patrimônio" (GONÇALVES, 2003, p. 22).

No entanto, considerando-se o espaço fragmentado, não há sobre ele uma ação que seja simultânea a todos os recortes. Mesmo que haja uma ação institucional que procure atingi-los de forma plena, cada parte ainda apresentará as suas idiossincrasias, pois a prática política, os interesses econômicos e o grau de compreensão sobre a importância da manutenção do patrimônio cultural são variáveis que determinam o resultado das ações sobre ele.

Considerando que os equipamentos patrimoniais urbanos são testemunhos materiais importantes, tanto pelo que representam para a sociedade, como do ponto de vista da ocupação e da permanência significativa no espaço da cidade é imprescindível que o direito à memória seja preservado e que se efetivem ações específicas que considerem e legitimem esses "lugares-distintos".

Inicialmente, esse lugar deve apresentar um traço que seja considerado relevante para a memória coletiva. Quanto mais abrangente for o reconhecimento dessa memória por parte da população, mais válidas serão as ações impetradas sobre ele. Depois, a relação deste traço com o ambiente construído deve possibilitar e incentivar a manutenção da sua integridade simbólica e a percepção dos significados dos elementos que a compõem.

Com essas características, o lugar possibilita ao indivíduo o (re)conhecimento da sua participação na cultura local, promove o bem estar social e contribui para o exercício de cidadania e, assim constituído, oferece à sociedade local e visitante, um espaço funcional para o desenvolvimento de ações educadoras e, conseqüentemente, turísticas. 


\section{REFERÊNCIAS}

ARANTES, Antonio A. (Org.). Produzindo o passado: estratégias de construção do patrimônio cultural. São Paulo: Brasiliense, 1984.

BARRETO, Margarita. Turismo e legado cultural. Campinas: Papirus, 2000.

BOURDIEU, Pierre. Contrafogos 2: por um movimento social europeu. Rio de Janeiro: Jorge Zahar, 2001.

CHAGAS, Mário. Memória política e política da memória. In: ABREU, Regina; CHAGAS, Mário (Orgs.). Memória e patrimônio: ensaios contemporâneos. Rio de Janeiro: DP\&A, 2003.

CHOAY, Françoise. A alegoria do patrimônio. São Paulo: Unesp, 2001.

CLAVAL, Paul. A geografia cultural. Florianópolis: UFSC, 2002.

COSGROVE, Denis. A geografia está em toda a parte: cultura e simbolismo nas paisagens humanas. In: CORRÊA, Roberto L.; ROSENDAHL, Zeny. Paisagem, tempo e cultura. Rio de Janeiro: EdUERJ, 1998.

CUCHE, Denys. A noção de cultura nas ciências sociais. 2. ed. Bauru: Edusc, 2002.

FELIX, Loiva O. História e memória: a problemática da pesquisa. Passo Fundo: Ediupf, 1998.

FONSECA, Maria Cecília L. O patrimônio em processo: trajetória da política federal de preservação no Brasil. Rio de Janeiro: UFRJ/IPHAN, 1997.

FREIRE, D.; PEREIRA, L. L. História oral, memória e turismo cultural. In: MORAES, A. C. R. Território e história no Brasil. São Paulo: Hucitec, 2002.

FURET, François. O historiador e a história: um relato de Françoise Furet. Estudos Históricos, Rio de Janeiro, n. 1, 1988.

GONÇALVES, José Reginaldo S. O patrimônio como categoria de pensamento. In: ABREU, Regina;
ESPAÇO URBANO: MEMÓRIA SOCIAL E PATRIMÔNIO CULTURAL

CHAGAS, Mário (Orgs.). Memória e patrimônio: ensaios contemporâneos. Rio de Janeiro: DP\&A, 2003.

GONDAR, Josaida. Lembrar e esquecer: desejo de memória. In: GONDAR, Josaida; COSTA, Icleia T. M. Memória e espaço. Rio de Janeiro: 7 letras, 2000.

GOTTDIENNER, Mark. A produção social do espaço urbano. São Paulo: Edusp, 1993.

HALBWACHS, Maurice. A memória coletiva. São Paulo: Vértice, 1990.

HAREVEN, Tamara K. Family time and industrial time. Londres, 1982.

HOBSBAWM, Eric. A era dos extremos: o breve século XX (1914-1991). São Paulo: Cia. das Letras, 1995.

JEUDY, Henry-Pierre. Memórias do social. Rio de Janeiro: Forense Universitária, 1990.

LEFEBVRE, Henry. O direito à cidade. São Paulo: Moraes, 1991.

LEPETIT, Bernard. Por uma nova história urbana. São Paulo: Edusp, 2001.

MACIEL JÚNIOR, Auterives. Nomadização dos espaços urbanos. In: COSTA, Icleia T. M.; GONDAR, Josaida. Memória e espaço. Rio de Janeiro: 7 letras, 2000.

NORA, Pierre. Entre a memória e a história: a problemática dos lugares. Projeto História, São Paulo, n. 10, 1995.

. Lês lieux de memórie. Tradução de Yara Aun Khoury. Paris: Gallimard, 1994.

OLIVEIRA, Lúcia L. (Org.). Cidade: história e desafios. Rio de Janeiro: FGV, 2002.

PINHEIRO, Augusto I. F. Aprendendo com o patrimônio. In: OLIVEIRA, L. L. (Org.). Cidade: história e desafios. Rio de Janeiro: FGV, 2002.

POULANTZAS, Nicos. O estado, o poder, o socialismo. 3. ed. Rio de Janeiro: Graal, 1985.

ROCHA, Ana Rita. As dialéticas da globalização: patrimônio cultural e turismo. Dissertação (Mestrado em Geografia) - Uniersidade Estadual de Ponta Grossa, Ponta Grossa, 2009. 
Leonel Brizola MonastiRski

RODRIGUES, M. Preservar e consumir: o patrimônio histórico e o turismo. In:

SANTOS, Milton. A natureza do espaço: técnica e tempo - razão e emoção. São Paulo: Edusp, 2002.

ROUSSO, H. Usos do passado na França de Hoje. In: SIMSON, V. MORAES, O. Os desafios contemporâneos da história oral. Campinas: $\mathrm{CMU} /$ UNICAMP, 1997.

SANT'ANA, Márcia. Memória, cidade e cidadania. In: COSTA, Icleia T. M; GONDAR, Josaida. Memória e espaço. Rio de Janeiro: 7 letras, 2000.

SOJA, Edward. Geografias pós-modernas: a reafirmação do espaço na teoria social crítica. Rio de Janeiro: Jorge Zahar, 1997.

VAINER, Carlos B. As escalas do poder e o poder das escalas: o que pode o poder local. In: IX ENCONTRO NACIONAL DA ANPUR. Anais..., 2001.

Recebido em 14/10/2009

Aceito em 06/12/2009 